www.conferenceie.ase.ro

\title{
BUILDING A BUSINESS MODEL FOR SERVICE OFFER INTEGRATOR IN CASE OF CLOUD-IOT BASED MONITORING
}

\author{
Gabriel NEAGU \\ National Institute for R\&D in Informatics, Bucharest, Romania \\ gabriel.neagu@ici.ro \\ Ionuț PETRE \\ National Institute for R\&D in Informatics, Bucharest, Romania \\ ionut.petre@ici.ro \\ Radu BONCEA \\ National Institute for R\&D in Informatics, Bucharest, Romania \\ radu.boncea@ici.ro \\ Dragoș Cătălin BARBU \\ National Institute for R\&D in Informatics, Bucharest, Romania \\ dragos.barbu@ici.ro \\ Mihail DUMITRACHE \\ National Institute for R\&D in Informatics, Bucharest, Romania \\ mihail.dumitrache@ici.ro
}

\begin{abstract}
The Cloud-IoT approach is an innovative solution to provide advanced information services, including monitoring services, in various application domains. The disruptive potential of this paradigm is based on the inherent complementarity of Cloud computing and Internet of Things technologies. This particularity generates mutual benefits for both technological domains and provides a significant potential for developing complex, value added services. Considering the multi-source specificity of these services, their integration in a coherent offer with the "single point of contact" principle in mind is expected to facilitate the market penetration of these services. The paper proposes the Cloud-IoT service offer integrator role implementing this principle. Its business profile is outlined and its interactions along the supply chain are identified. Based on this information the business model specifications are presented in terms of customer segments, value propositions, channels, customer relationship, revenue streams, key resources, key activities, key partnerships, and cost structure.
\end{abstract}

Keywords: business model, Cloud computing, integrated service offer, Internet of Things, monitoring services.

JEL classification: D23, L21, L86

DOI: $10.12948 / \mathrm{ie} 2019.02 .05$

\section{Introduction}

The idea of combining Cloud computing and Internet of Things (IoT) technologies for monitoring services is based on their complementarities in terms of computational and storage capabilities (virtually unlimited vs. limited), components involved (virtual resources vs. real things), coverage (ubiquitous vs. limited), Internet usage (service delivery vs. data concentration and transmission) [1]. These complementarities generate obvious benefits: the scalable capabilities and resources of the Cloud compensate technological constraints of IoT, while the IoT capability to interact with real world things in a distributed and dynamic manner facilitates the diversification of Cloud provided services [2]. The interest for this approach is 
illustrated by a large diversity of solutions, as for example the architectures CloudThings [3], Cloud of Things [4], Sensing as Service [5]. The role of reference architecture in building compliant solutions in this field is argued in [6]. The implementation of such architectural solution for an IoT platform dedicated to the Cloud of Things services in health monitoring is presented in [7].

Besides their technical excellence, the successful valorisation on the market of a Cloud-IoT monitoring services depends on great extent of the accessibility of these services. The paper proposes a new kind of supplier that should have necessary expertise to integrate Cloud-IoT component services and to isolate the customer from technical details behind its access to final service results. The viability of this new role on the market is influenced by the capacity of the adopted business model (BM) to cover and orchestrate all specific contributions and interactions.

The aim of this paper is to define the main characteristics of this BM, adapted to the specificity of the service offer integrator (SOI) role in the field of Cloud-IoT based monitoring. The remaining part of the paper is structured as follows: section 2 motivates the opportunity of the integrated service offer and outlines the SOI business profile. Section 3 details the SOI business interactions. The specifications of the SOI business model are provided in section 4. Some concluding remarks are presented in the final section.

\section{SOI rationale for Cloud-IoT based monitoring}

\subsection{Integrated service offer}

According to [5], the provision of Cloud-IoT services is based on three contributors: the sensor device owner (SDO), the Cloud-IoT data publisher (CIP) and the extended service provider (ESP). By ownership, the sensors might be personal, or they may belong to a private or public organization, or to a commercial sensor provider. The SDO decides whether to publish in cloud the data collected from its sensor devices and defines restrictions and conditions related to this offer. The CIP is a cloud provider that operates a Cloud-IoT platform and is able to publish sensor data in agreement with SDO. The ESP provides applications for advanced data analytics and visualization, to process sensor data published in cloud according to users' requirements. On the customer's side, in order to be able to access and to interpret the service results, the sensor data consumer (SDC) should interact with all these providers and should be able to aggregate their offers according to its needs. To avoid this inconvenience, the role of the service offer integrator is proposed, with the mission to implement the "single point of contact" principle in relation with SDCs.

\subsection{Generic business profile}

The SOI business profile is closed to the classical Full Service Provider (FSP) model, described in [8]. In synthesis, the features of this profile relevant in our case are as follows. The aim is to provide total coverage of customer needs in a particular domain, via a single point of contact. As derived from this aim, the main objectives are: to own the primary customer relationship; to meet the complete needs of a target customer segment; and to integrate its own products and services with complementary products and services of third-party providers.

The added value is generated by an extended offer, sourced either internally (from the FSP) or external (from third-party providers).

The third-party providers are fully integrated into the full-service provider's offerings. Some of them may have a relationship with the customer but under the umbrella of the FSP. The direct customer's interaction flow (requests for information, orders, and money) is connected with the FSP, and then with third-party providers. 
The most common sources of revenue are: transaction fees, advertising fees from third-party providers, fees for selling data about customers, annual membership fees.

The critical success factors include: create credibility and trust necessary for a customer to consider the company offer covering her/his complete needs in the domain, be able to integrate and consolidate the offering of third parties into a single channel dedicated to customer relationship in the domain, be capable to configure an integrated offer and mitigate potential tension between component (internal and external) products/services, maintain and use a customer relationship database to be better informed than other similar players, anticipate changes in customer needs, promote and enforce reliable policies to protect both providers' interests and customers' interests.

The domains to implement this business profile should be broad enough to allow a full-service provider to include enough products and services to create a strong value proposition. This feature will assure also a reasonably low number of such providers. It is important that the convenience, which is an implicit goal of an integrated offer, is among most relevant attraction for the customer in the given domain. The list of such domains includes: financial services, health care, education, entertainment, travel, and government services.

\section{SOI business interactions}

The main business interactions of the SOI are presented in Figure 1.

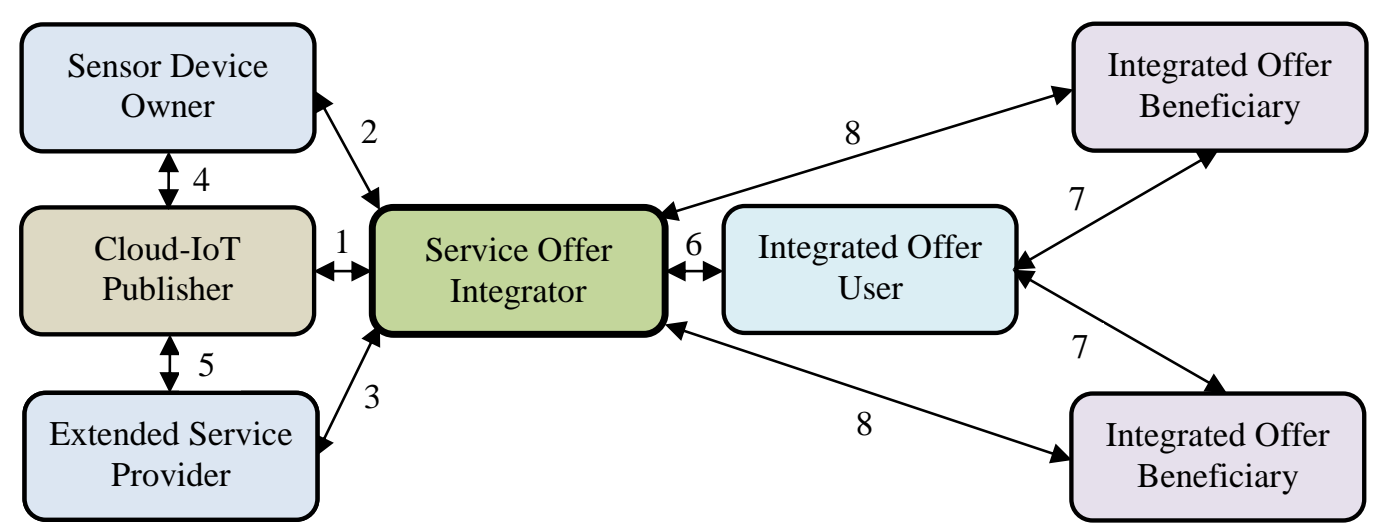

Figure 1. SOI business interactions

After the identification of a market opportunity and the analysis of its requirements, the SOI negotiates the IoT data publication in cloud (1), the availability of necessary sensor devices (2) and the access to value-added services for sensing data analysis and visualization (3). Then, the CIP and the SDO establish and validate technical conditions to integrate identified SDO devices in the IoT platform (4). In a similar way, the requirements for installation and execution in cloud of value added applications are negotiated between the CIP and the ESP (5). It should be mentioned that there may be different approaches to implement these roles and to simplify their interactions. For example the service company playing the SOI role might decide to play also other roles, e.g. the ESP. Even more probably the CIP, as having the most substantial contribution in the integrated offer could play also the SOI role.

On the customer side, by implementing the SOI role, the SDC is represented by the Integrated Offer User (IOU) and the Integrated Offer Beneficiary (IOB). The problem that has to be solved using the Cloud-IoT services belongs to the IOB. The IOU has the expertise to understand and interpret the results provided by the Cloud-IoT services and according to this interpretation it is able to recommend to the IOB a plan of actions. In this respect, the IOU negotiates with the SOI the contract, which stipulates the configuration of the integrated service offer, the 
conditions of its activation and the access rights to the Cloud-IoT infrastructure, according to requirements derived from the analysis of the beneficiary's problem (6). Based on this contract, the IOU concludes a subsidiary contract with the IOB regarding the obligations IOB has in order to activate for a given period of time the negotiated integrated serve offer in the contract (6), as well as the outputs the IOU will deliver during the respective period of time (7). Finally the IOB concludes the contract (8) with the SOI to implement the conditions stipulated in contract (6) for the service activation.

For example, in case of air pollution monitoring in a large municipality, the city hall is the IOB and a local organization specialized in air pollution evaluation (e.g. a research organization or SME specialized in environment protection) will play the role of IOU. The health monitoring is another specific case, where the IOB is a physical person (the patient) and the IOU is a small medical unit providing remote monitoring services. In this case it is obvious that the initiative of activating the integrated service offer belongs to the IOU, while the IOB is playing a passive role with the aim to benefit of physician's advices. For a large medical unit providing in house monitoring services this scenario could be simplified in the sense that the SOI role might be played by the own IT department.

\section{Specifications of the Cloud-IoT SOI-BM}

The main reason of a business model is to describe the rationale of how the value is created, delivered, and captured. Current specifications for the SOI-BM are based on the business model structure proposed in [9], which includes nine main building blocks. A synthetic presentation is given in Table 1.

Table 1. Business model building blocks

\begin{tabular}{|l|l|l|}
\hline \multicolumn{1}{|c|}{ Name } & \multicolumn{1}{|c|}{ Definition } & \multicolumn{1}{c|}{ Details } \\
\hline $\begin{array}{l}\text { 1. Customer } \\
\text { segments }\end{array}$ & $\begin{array}{l}\text { different groups of people or } \\
\text { organizations an enterprise } \\
\text { aims to reach and serve }\end{array}$ & $\begin{array}{l}\text { Typology: mass market, niche market, segments with } \\
\text { slightly different needs and problems, segments with very } \\
\text { different needs and problems }\end{array}$ \\
\hline $\begin{array}{l}\text { 2. Value } \\
\text { propositions }\end{array}$ & $\begin{array}{l}\text { products and services that } \\
\text { create value for a specific } \\
\text { customer segment }\end{array}$ & $\begin{array}{l}\text { Sources of value: newness, performance, design, } \\
\text { customization, price, cost reduction, risk reduction, } \\
\text { accessibility, usability. }\end{array}$ \\
\hline 3. Channels & $\begin{array}{l}\text { the way a company } \\
\text { communicates with and } \\
\text { reaches its customer } \\
\text { segments (direct or indirect, } \\
\text { own or partners) to deliver a } \\
\text { value proposition }\end{array}$ & $\begin{array}{l}\text { Channel phases: rise awareness, help customers evaluate } \\
\text { the proposed value, allow customers to purchase specific } \\
\text { products and services, deliver a value proposition to } \\
\text { customers, and provide post-purchase customer support. }\end{array}$ \\
\hline $\begin{array}{l}\text { 4. Customer } \\
\text { relationship }\end{array}$ & $\begin{array}{l}\text { types of relationships a } \\
\text { company establishes with } \\
\text { specific customer segments }\end{array}$ & $\begin{array}{l}\text { Typology: personal assistance (based on human } \\
\text { interaction), dedicated personal assistance (to an } \\
\text { individual client), self-service (no direct relationship), } \\
\text { automated services (customized self-service), } \\
\text { communities (helping companies better understand their } \\
\text { customers), co-creation (creating value with customers). }\end{array}$ \\
\hline $\begin{array}{l}\text { 5. Revenue } \\
\text { streams }\end{array}$ & $\begin{array}{l}\text { the cash a company generates } \\
\text { from each customer segment, } \\
\text { by various ways }\end{array}$ & $\begin{array}{l}\text { Typology: asset sale (selling ownership rights to a } \\
\text { physical product), usage fee (specific to a particular } \\
\text { service), subscription fees (selling continuous access to a } \\
\text { service), lending/renting/leasing (temporarily granting } \\
\text { someone the exclusive right to use a particular asset for a } \\
\text { fixed period), licensing (giving customers permission to } \\
\text { use protected intellectual property), brokerage fees }\end{array}$ \\
\hline
\end{tabular}


wWw.conferenceie.ase.ro

\begin{tabular}{|l|l|l|}
\hline & $\begin{array}{l}\text { (intermediation services performed on behalf of two or } \\
\text { more parties), advertising fees. }\end{array}$ \\
\hline $\begin{array}{l}\text { 6. Key } \\
\text { resources }\end{array}$ & $\begin{array}{l}\text { what assets are required by } \\
\text { the business model }\end{array}$ & $\begin{array}{l}\text { Typology: physical assets (e.g. manufacturing facilities, } \\
\text { buildings, distribution networks), intellectual resources } \\
\text { (e.g. brands, proprietary knowledge, patents, copyrights, } \\
\text { partnerships, customer databases), human resources (for } \\
\text { knowledge-intensive and creative industries), financial } \\
\text { resources. }\end{array}$ \\
\hline $\begin{array}{l}\text { 7. Key } \\
\text { activities }\end{array}$ & $\begin{array}{l}\text { what a company has to do } \\
\text { according to its business } \\
\text { model }\end{array}$ & $\begin{array}{l}\text { Examples: production related activities, activities } \\
\text { providing solutions to customers needs (in case of service } \\
\text { companies), platform supporting activities (maintenance, } \\
\text { management, operation, promotion). }\end{array}$ \\
\hline $\begin{array}{l}\text { 8. Key } \\
\text { partnerships }\end{array}$ & $\begin{array}{l}\text { suppliers and partners that are } \\
\text { important for key resources } \\
\text { and key activities of the } \\
\text { business model }\end{array}$ & $\begin{array}{l}\text { Main benefits: optimizing the allocation of resources and } \\
\text { activities (e.g. outsourcing or sharing infrastructure), } \\
\text { reduction of risk and uncertainty through strategic } \\
\text { alliances, acquisition of particular/specific resources and } \\
\text { activities (for access to knowledge, licenses, or customer } \\
\text { segments). }\end{array}$ \\
\hline $\begin{array}{l}\text { 9. Cost } \\
\text { structure }\end{array}$ & $\begin{array}{l}\text { operation costs for BM (key } \\
\text { resources, activities and } \\
\text { partnerships): variable or } \\
\text { fixed costs, economies of } \\
\text { scale, economies of scope }\end{array}$ & $\begin{array}{l}\text { Main cost models: cost-driven model (focused on low } \\
\text { price value propositions and extensive outsourcing) and } \\
\text { value-driven model (oriented on value creation and highly } \\
\text { personalized product and services). }\end{array}$ \\
\hline
\end{tabular}

Note: adapted from [9].

Based on this structure, the proposed specifications for the SOI-BM are as follows.

Customer segments: the segments with very different needs and problems is most suitable: even that the integrated service offer structure is the same for any application domain, there might be significant differences in requirements along the entire data flow, from sensor devices and data collection, through data storage, cleaning and aggregation, data event processing, up to the value added applications layer for analytical processing and visualization.

Value propositions: the performance of the Cloud-IoT infrastructure, customization of value added services, service accessibility including data privacy and integrity issues, and usability of provided results should be considered first in creating value for its customers.

Channels: the own and direct channel should be the choice as an efficient customer relationship management is a key success factor for its business profile. Regarding channel phases, as the provision of Cloud-IoT services is an emerging market, the SOI channel should carefully implement and cover all of them, with a specific attention paid to first two ones.

Customer relationship: as the SOI-BM offer should be highly customized, the direct, personal relation with each customer is highly desirable. Also, as this dialogue is expected to provide an important input for SOI itself in understanding specific needs of this emerging market and in diversifying value added components of its offer, the co-creation dimension of the customer relationship should be considered as an another important critical success factor.

Revenue streams: from customers' side, the SOI-BM revenue streams are specific to service providers: usage fee or subscription fees, depending on how the customer needs to access the service results. From providers' side, these streams are specific to SOI business profile, mentioned in the previous section.

Key resources: the key resources are the Cloud-IoT infrastructure, the human resource expertise of providing and integrating infrastructure services and advanced data analytics and visualization services, as well as the intellectual resources represented by the licensed software. 
Key activities: SOI is a service company, therefore its key activities are those dedicated to solve customer needs.

Key partnerships: optimizing the allocation of resources and activities achieved by complementarities of proposed contributions to the integrated service offer, reduction of risk and uncertainty specific to a long term partnership with the owners of key resources: the distributed infrastructure and the value added applications.

Cost structure: the cost structure includes fixed costs for infrastructure operation, variable costs for sensor devices and value-added applications. Also, the economy of scale is specific to this business model as soon as the basic idea behind the Cloud-IoT solution is better valorisation of IoT data through their sharing between more interested users.

\section{Conclusions}

The paper proposes the service offer integrator role having its main mission to achieve the match between requirements of a problem formulated on the market and the potential solution based on Cloud-IoT services. To consolidate this provider's place in the supply chain, its business profile is identified, its business interactions are detailed and the proposed business model is described. Based on these contributions, an informatics solution is currently under development to support the efficient management of SOI activities according to the proposed business model.

\section{References}

[1] A. Botta, W. de Donato, V. Persico, and A. Pescapé, "Integration of Cloud computing and Internet of Things: A survey," Future Generation Computer Systems, vol. 56, pp. 684-700, March 2016.

[2] S. Distefano, G. Merlino, and A. Puliafito, "Enabling the Cloud of Things," in Proc. The Sixth IEEE Int. Conference on Innovative Mobile and Internet Services in Ubiquitous Computing (IMIS), Palermo, Italy, 2012, pp. 858-863.

[3] J. Zhou et al., "Cloudthings: A common architecture for integrating the Internet of Things with Cloud computing," in Proc. The IEEE 17th Int. Conference on Computer Supported Cooperative Work in Design, Whistler, Canada, 2013, pp.651-657.

[4] M. Aazam, I. Khan, A. Alsaffar, E-N. Huh, "Cloud of things: integrating internet of things and cloud computing and the issues involved," in Proc. The IEEE Int. Bhurban Conference on Applied Sciences \& Technology, Islamabad, Pakistan, 2014, pp. 414-419.

[5] C. Perera, A. Zaslavsky, P. Christen, and D. Georgakopoulos, "Sensing as a Service Model for Smart Cities Supported by Internet of Things," Transactions on Emerging Telecommunications Technologies, Special Issue: Smart Cities - Trends \& Technologies, vol. 15, no. 1, pp. 81-93, January 2014.

[6] M. Zamfir, V. Florian, A. Stanciu, G. Neagu, S. Preda, G. Militaru, "Towards a Platform for Prototyping IoT Health Monitoring Services," in Exploring Services Science Book series: Lecture Notes in Business Information Processing, vol. 147, Springer, pp. 522-533.

[7] G. Neagu, V. Florian, A. Stanciu, S. Preda, "Sensing as a Service Approach in Health Monitoring," in Proc. of the 15th IEEE RoEduNet Conference: Networking in Education and Research, Bucharest, Romania, 2016, pp. 225-229.

[8] P. Weill Peter and M. Vitale, We have moved place to space: migrating to e-business model. Harvard Business School Press, Boston, USA, 2001.

[9] A. Osterwalder and Y. Pigneur, Business Model Generation. John Wiley \& Sons, 2010, ISBN: 978-0470-87641-1. 